\title{
Necessidade do ajuste de curvaturas na tomada de decisão da melhor configuração de paredes de alvenaria para o conforto térmico
}

\author{
Geferson da Silva* Ana Júlia da Silva* Natani Lacerda* Peterson Avi** \\ Depto. de Ciências Exatas e Engenharias, DCEEng, UNIJUÍ, CEP: 98700-000, Ijuí, RS \\ E-mail: geferson_gustavo@hotmail.com; ana_juliass@yahoo.com.br; natty.lacerda@hotmail.com; \\ peterson.avi@unijui.edu.br
}

\begin{abstract}
RESUMO
Este trabalho surgiu de uma atividade proposta na disciplina de Cálculo Numérico, presente no curso de Licenciatura em Matemática da Universidade Regional do Noroeste do Estado do Rio Grande do Sul - UNIJUÍ, a qual objetivava aplicar conceitos matemáticos em diferentes áreas do conhecimento como, por exemplo, Engenharia, Física ou Economia, sendo que estas áreas se utilizam de dados provenientes de atividades experimentais, onde através destes tem a possibilidade de analisar comportamentos de um determinado fenômeno, em um período ou intervalo de tempo. No entanto, em toda atividade experimental ou de retirada de dados, existe o fator erro que pode ser consequência da calibragem do equipamento, à forma como os dados foram analisados e ainda aos critérios de arredondamento desses valores.

Dessa maneira, foi utilizado um ajuste de curvaturas que procura a curva que melhor representa os dados reais/experimentais, ao qual dependendo do coeficiente de determinação encontrado representa com confiabilidade a relação entre as variáveis até mesmo fora do intervalo utilizado. Portanto, para a determinação da função que extrapole os limites conhecidos, foi criado um algoritmo no Matlab, o qual se utiliza dos dados experimentais para ajustar a curva que melhor representa os mesmos considerando a relação entre as variáveis. Assim, esse procedimento foi aplicado em uma situação, a qual analisou o comportamento de diversas configurações de paredes de alvenaria em virtude da variação de temperatura em períodos de tempos determinados, considerando o melhor conforto térmico.

Neste trabalho foi analisada apenas uma configuração de parede de alvenaria, somente como forma de aplicar o ajuste polinomial de curvaturas, sendo que os dados utilizados foram retirados da literatura onde para determinar a melhor curva foi utilizado o método dos coeficientes de determinação $\left(\mathrm{R}^{2}=1-\mathrm{SQE} / \mathrm{SQT}\right)$. Esta técnica consiste na razão entre a soma dos quadrados dos erros $\left(\mathrm{SQE}=\Sigma(\mathrm{y}-\widehat{\mathrm{y}})^{2}\right)$ e a soma do quadrado das diferenças em relação à média $\left(\mathrm{SQT}=\Sigma(\mathrm{y}-\overline{\mathrm{y}})^{2}\right)$, sendo este valor (razão) subtraído de 1 . Ressalta-se que o $\bar{y}$ representa a razão entre o somatório dos pontos não ajustados e o número de dados existentes e o y representa o y calculado. Portanto, quanto mais próximo de 1, melhor é o ajuste.

Segundo a Literatura [2], após ter sido inserido os termômetros na parede de alvenaria, a mesma foi acomodada dentro de uma câmara térmica com uma fonte de calor. Esta câmara estava devidamente isolada do ambiente, para que não existissem influências externas na amostra a ser analisada, pois segundo Costa [1], a temperatura tenderá a desaparecer, pela passagem de calor de uma região à outra, sempre que existir uma diferença de temperatura entre duas regiões do espaço. É valido ressaltar que a intensidade de calor apresenta valores variando do mínimo ao máximo, conforme descrito na Tabela 1, retirada da literatura [2].
\end{abstract}

\begin{tabular}{c|c|c|c}
\hline Estágio da Temperatura & Tempo $(\mathrm{h})$ & Regulagem - dimmer & Intensidade de calor \\
\hline 1 & 0 & Acionamento I & Mínima \\
\hline 2 & 2 & Acionamento II & Baixa \\
\hline 3 & 4 & Acionamento III & Média \\
\hline 4 & 6 & Acionamento IV & Máxima \\
\hline 5 & 8 & Acionamento V & Média \\
\hline 6 & 10 & Acionamento VI & Baixa \\
\hline 7 & 12 & Acionamento VII & Mínima \\
\hline 8 & 14 & Desativação & Sem intensidade de calor \\
\hline
\end{tabular}

Tabela 1. Registro dos estágios de intensidade de calor atuantes na amostra.

*Alunos do Curso de Matemática Licenciatura

**Professor MSc. Orientador - UNIJUÍ 
Após um período de 16 horas (840 minutos), têm-se os dados provenientes dos sensores de temperatura em virtude da posição dos termômetros e da variação do tempo, que estão descritos nas Tabelas 2, retirada da literatura [2]. E a Tabela 3 (elaborada pelos autores) representa os valores corrigidos a partir do algoritmo utilizado para o ajuste.

\begin{tabular}{|c|c|c|c|c|c|c|}
\hline \multirow{2}{*}{$\begin{array}{c}\text { Tempo } \\
\text { (h) }\end{array}$} & \multicolumn{5}{|c|}{ Parede 3- Algumas Temperaturas Lidas } \\
\cline { 2 - 7 } & TP8 & TP1 & $\ldots$ & TP4 & TP5 & TP9 \\
\hline $00: 00$ & 17,1 & 17,3 & $\ldots$ & 18,0 & 19,6 & 18,0 \\
\hline $00: 30$ & 17,6 & 17,0 & $\ldots$ & 19,6 & 20,6 & 31,9 \\
\hline $01: 00$ & 18,4 & 17,9 & $\ldots$ & 19,9 & 22,7 & 34,0 \\
\hline $01: 30$ & 18,3 & 17,9 & $\ldots$ & 20,2 & 23,5 & 35,5 \\
\hline $02: 00$ & 18,1 & 18,0 & $\ldots$ & 21,3 & 24,2 & 37,7 \\
\hline $02: 30$ & 18,6 & 18,4 & $\ldots$ & 22,7 & 26,8 & 47,6 \\
\hline $03: 00$ & 19,7 & 18,7 & $\ldots$ & 24,3 & 28,9 & 48,6 \\
\hline $03: 30$ & 19,7 & 18,5 & $\ldots$ & 25,9 & 29,8 & 50,0 \\
\hline $04: 00$ & 19,7 & 18,9 & $\ldots$ & 26,4 & 31,2 & 53,7 \\
\hline $04: 30$ & 20,4 & 19,5 & $\ldots$ & 28,4 & 33,7 & 62,5 \\
\hline $05: 00$ & 20,7 & 19,3 & $\ldots$ & 30,3 & 35,9 & 65,8 \\
\hline$\rrbracket$ & $₫$ & $\rrbracket$ & $₫$ & $\rrbracket$ & $\rrbracket$ & $\rrbracket$ \\
\hline $13: 00$ & 24,7 & 25,0 & $\ldots$ & 36,2 & 36,2 & 43,0 \\
\hline $13 \geqq 30$ & 24,9 & 25,4 & $\ldots$ & 35,7 & 35,4 & 43,6 \\
\hline $14: 00$ & 24,7 & 25,2 & $\ldots$ & 35,2 & 35,2 & 42,5 \\
\hline $14: 30$ & 24,7 & 25,8 & $\ldots$ & 34,2 & 33,4 & 32,8 \\
\hline $15: 00$ & 24,9 & 25,0 & $\ldots$ & 33,6 & 32,6 & 31,2 \\
\hline $15: 30$ & 24,7 & 25,4 & $\ldots$ & 32,5 & 31,7 & 30,7 \\
\hline $16: 00$ & 24,1 & 25,7 & $\ldots$ & 31,2 & 30,5 & 29,3 \\
\hline
\end{tabular}

Tabela 2. Dados Lidos.

\begin{tabular}{|c|c|c|c|c|c|c|}
\hline \multirow{2}{*}{$\begin{array}{c}\text { Tempo } \\
\text { (h) }\end{array}$} & \multicolumn{6}{|c|}{ Parede 3 - Algumas Temperaturas Corrigidas } \\
\hline & TP8 & TP1 & $\ldots$ & TP4 & TP5 & ТP9 \\
\hline $00: 00$ & 17,0 & 17,2 & $\ldots$ & 18,0 & 19,5 & 18,5 \\
\hline $00: 30$ & 17,8 & 17,1 & $\ldots$ & 19,3 & 20,8 & 31,2 \\
\hline 01:00 & 18,5 & 17,6 & $\ldots$ & 19,9 & 22,2 & 34,5 \\
\hline $01: 30$ & 18,2 & 18,0 & $\ldots$ & 20,5 & 23,5 & 36,1 \\
\hline 02:00 & 18,4 & 18,2 & $\ldots$ & 21,3 & 24,9 & 38,9 \\
\hline $02: 30$ & 18,8 & 18,3 & $\ldots$ & 22,5 & 26,4 & 43,2 \\
\hline 03:00 & 19,2 & 18,4 & $\ldots$ & 23,9 & 28,1 & 48,2 \\
\hline 03:30 & 19,6 & 18,6 & $\ldots$ & 25,5 & 29,9 & 53,1 \\
\hline 04:00 & 19,9 & 18,9 & $\ldots$ & 27,4 & 31,8 & 57,8 \\
\hline 04:30 & 20,2 & 19,2 & $\ldots$ & 28,7 & 33,8 & 60,5 \\
\hline $05: 00$ & 20,5 & 19,6 & $\ldots$ & 30,3 & 35,6 & 62,9 \\
\hline § & \# & \pm & $\equiv$ & $\equiv$ & 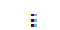 & $\equiv$ \\
\hline 13:00 & 24,5 & 25,2 & $\ldots$ & 36,3 & 36,3 & 44,9 \\
\hline $13 \approx 30$ & 24,6 & 25,2 & $\ldots$ & 35,6 & 35,5 & 42,4 \\
\hline 14:00 & 24,7 & 25,3 & $\ldots$ & 35,0 & 34,7 & 39,2 \\
\hline $14: 30$ & 24,8 & 25,4 & $\ldots$ & 34,3 & 33,7 & 35,5 \\
\hline $15: 00$ & 24,8 & 25,3 & $\ldots$ & 33,5 & 32,6 & 31,8 \\
\hline $15: 30$ & 24,7 & 25,2 & $\ldots$ & 32,4 & 31,5 & 29,3 \\
\hline 16:00 & 24,0 & 25,7 & $\ldots$ & 31,1 & 30,5 & 29,6 \\
\hline
\end{tabular}

Tabela 3. Dados Corrigidos.

A Tabela 2 apresenta os dados decorrentes de uma amostragem laboratorial, retirada da literatura [2]. A mesma possui erros inerentes aos equipamentos, variação de estágios de intensidade de calor, arredondamento de casas decimais e fatores humanos. Portanto, foi realizado um ajuste polinomial destes dados que se encontram descritos na Tabela 3, a qual apresenta maior confiabilidade para uma previsão de comportamento durante a transição de calor e geração do conforto térmico.

Utilizando o Matlab e um algoritmo para o ajuste polinomial, foram alterados os dados presentes na Tabela 2, a fim de tornar os valores mais precisos, uma vez que, foram consideradas funções similares que possuíam valores de $R^{2}$ variando entre 0,9771 a 0,9982 , ou seja, valores muito próximos a 1, o que indica uma margem mínima de erros. Nesse sentido, encontramos no polinômio de grau dez, a curvatura que melhor ajustou-se aos valores. Percebeu-se, portanto, que no caso específico deste trabalho, o ajuste por extrapolação polinomial não gerou alteração significativa a ponto de ser escolhida uma configuração de parede em detrimento de outra. Porém, caso se considerasse outras situações que apresentassem estruturas, as quais respondessem a qualquer mudança de temperatura, se perceberia que $o$ melhor ajuste aos dados experimentais alteraria consideravelmente a escolha ou a tomada de decisão a respeito de um modelo a ser seguido, como por exemplo, em situações presentes na indústria de alimentos, cuja menor mudança de temperatura em uma embalagem, provoca resultados significativos na composição, aparência ou até mesmo qualidade do produto.

Palavras-chave: Extrapolação de dados, Cálculo Numérico, Engenharia.

\section{Referências}

[1] E. C. D Costa, Física aplicada à construção: conforto térmico, Blücher, São Paulo, 1974.

[2] R. F. Rupp, Análise da transferência de calor em paredes compostas por tijolos maciços. UNIJUÍ, Ijuí, 2009. 